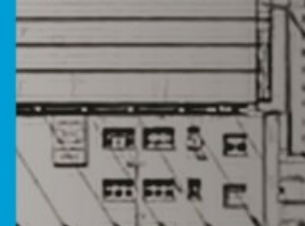

\title{
Qualidade de Vida Urbana como Política Pública: o movimento cidades saudáveis
}

Urban Quality of Life and Public Policy: movement healthy cities

Calidad de vida urbana y política pública: los municipios saludables

Douglas Gallo

Professor Mestre, IFSP, Brasil

Doutorando em Urbanismo, PROURB/UFRJ, Brasil douglas.luciano@yahoo.com.br

Eliane Bessa

Professora Doutora, PROURB/UFRJ, Brasil. elianesilbessa@gmai.com 


\section{RESUMO}

O objetivo deste ensaio é discutir os conceitos de política pública e promoção da saúde, apresentando-se como referencial para a melhoria da qualidade de vida urbana e criação de cidades mais saudáveis. Partiu-se do pressuposto que as políticas públicas são a forma de intervenção do Estado na realidade local, materializando-se em investimentos e regulamentações, sendo fruto da relação entre Estado, classes sociais e sociedade civil. Outro conceito chave foi o da qualidade de vida urbana, ligada diretamente à percepção dos indivíduos e ao seu ambiente físico, particularmente as cidades. A promoção da saúde é um enfoque generalista que mesmo surgindo dentro do setor saúde considera a intersetorialidade como fundamental para a qualidade de vida das populações. $O$ movimento das cidades saudáveis foi aqui estudado por considerar um conjunto de políticas públicas, com foco na qualidade de vida e promoção da saúde. Cidades Saudáveis, mais que um conceito, é uma estratégia de promoção da saúde cujo objetivo é a melhoria da qualidade de vida da população.

PALAVRAS-CHAVE: Qualidade de vida urbana. Políticas públicas. Cidades saudáveis.

\section{ABSTRACT}

This study aimed to discuss the concepts of public policy and health promotion, presenting itself as a reference for improving the quality of urban life and creating healthier cities. He started from the assumption that public policies are a form of state intervention in local reality, materializing in investments and regulations, being the result of the relationship between state, social classes and civil society. Another key concept was the quality of urban life, directly linked to the perception of individuals and their physical environment, particularly cities. Health promotion is a general approach that even emerging within the health sector considers intersectoriality as fundamental to the quality of life of the population. The movement of healthy cities was studied here by considering a set of public policies, focusing on quality of life and health promotion. Healthy Cities, more than a concept, it is a health promotion strategy aimed at improving the population's quality of life.

KEYWORDS: Quality of urban life. Public policy. Healthy cities.

\section{RESUMEN}

El propósito de este ensayo es discutir los conceptos de orden público y de promoción de la salud, que se presenta como una referencia para la mejora de la calidad de vida urbana y la creación de ciudades más saludables. Se partió de la hipótesis de que las políticas públicas son una forma de intervención del Estado en la realidad local, la materialización de las inversiones y los reglamentos, siendo el resultado de la relación entre el Estado, las clases sociales y la sociedad civil. Otro concepto clave es la calidad de la vida urbana, directamente ligado a la percepción de los individuos y su entorno físico, en particular las ciudades. Promoción de la salud es un enfoque general que incluso emergente dentro del sector de la salud considera la intersectorialidad como fundamental para la calidad de vida de la población. Se estudió el movimiento de ciudades saludables aquí considerando un conjunto de políticas públicas, centrándose en la calidad de la promoción de la vida y la salud. Ciudades saludables, más que un concepto, es una estrategia de promoción de la salud dirigida a mejorar la calidad de vida de la población.

PALABRAS CLAVE: Calidad de vida urbana. Políticas públicas. Ciudades saludables. 


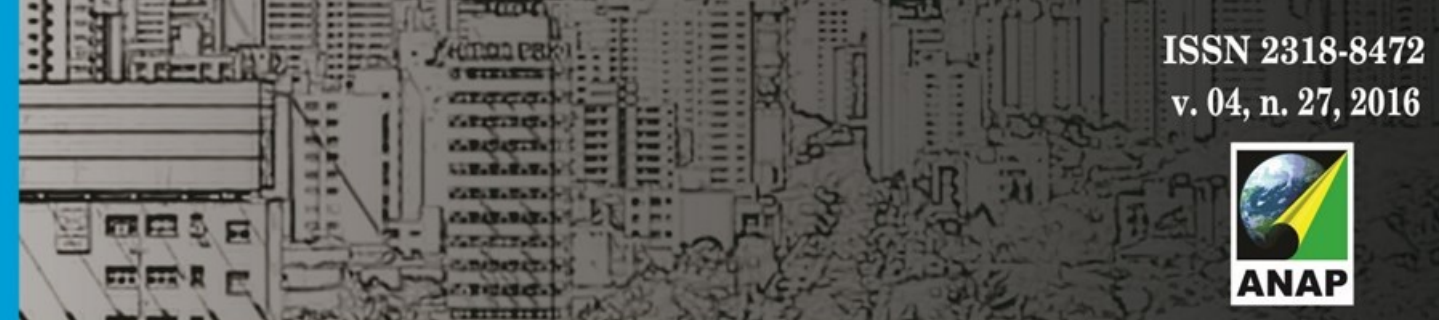

Revista Nacional de Gerenciamento de Cidades

\section{INTRODUÇÃO}

A ideia deste artigo surgiu da proposta de discussão dos conceitos de Política Pública e Qualidade de Vida Urbana durante o Seminário Teórico Avançado "Estado, Políticas Públicas e Cidadania". Optou-se por aprofundar a discussão do Movimento Cidades Saudáveis por entender que este engloba uma redefinição e adoção de políticas públicas com foco na Promoção da Saúde tendo como objetivo efetivo a melhoria da qualidade de vida urbana dos cidadãos.

O termo Promoção da Saúde surge pela primeira vez no Canadá, em 1974, no chamado Informe Lalonde, onde o então Ministro da Saúde, Marc Lalonde, demonstra a partir de dados sanitários que os investimentos efetuados exclusivamente em assistência não seriam capazes de assegurar a saúde de uma população. Lalonde mostrou que a política pública de saúde necessitava de mudanças, não apenas na forma de agir, mas especialmente na maneira de olhar e pensar a saúde e os problemas de saúde.

Como consequência em 1986 foi realizada a I Conferência Internacional da Saúde, no Canadá, cujo principal resultado foi o documento "Carta de Ottawa", segundo a qual, promoção da saúde consiste em capacitar a população para melhorar suas condições de saúde e aumentar seu controle sobre as mesmas. Hoje, trinta anos após esta primeira conferência, o conceito relaciona-se também com novas discussões sobre empoderamento e participação social.

Para que uma cidade, município ou comunidade possam ser considerados saudáveis entendese que seja necessária uma vontade política do Estado e suas instituições e da sociedade civil, em prol da efetivação de políticas públicas intersetoriais com foco na qualidade de vida urbana. O objetivo do presente ensaio é discutir os conceitos de política pública e promoção da saúde, apresentando-se como referencial para a melhoria da qualidade de vida urbana e criação de cidades mais saudáveis.

\section{AS POLÍTICAS PÚBLICAS COMO CONSTRUÇÃO COLETIVA}

As Políticas Públicas são ações que nascem do contexto social, mas que ao passar pela instância estatal, como decisão de intervenção pública numa determinada realidade social, materializam-se como investimentos ou regulamentações administrativas. Estas são o resultado da dinâmica do jogo de forças entre grupos políticos e econômicos, classes sociais e sociedade civil organizada, no âmbito das relações de poder.

De acordo com Boneti (2007) é na relação entre o Estado, as classes sociais e a sociedade civil que se originam os agentes definidores das políticas públicas. Desta forma entende-se que as políticas públicas não são definidas tendo como parâmetro unicamente o bem comum, nem tão pouco os interesses específicos de uma classe, como se o Estado estivesse a serviço da classe dominante. É na complexidade da relação intrínseca entre estes entes e agentes que ocorre a elaboração e operacionalização das políticas públicas. 
As instituições públicas direcionam as Políticas Públicas para a construção do tipo de sociedade que se deseja. O projeto do capitalismo global é o do Estado Mínimo, cuja racionalidade instrumental concorrencial tem no mercado o princípio de autorregulação da esfera econômica e social. A universalização de um padrão tecnológico, de hábitos culturais e de consumo passa a se constituir em um padrão de referência. Existe uma hegemonia mundial que alia decisões políticas aos projetos econômicos, definindo políticas públicas que viabilizam os empreendimentos.

Dentro da moderna luta capitalista contra a desigualdade e a exclusão, ocorre uma negação das diferenças que opera num projeto de homogeneização, partindo de uma ideia de universalismo própria. A tentativa da ordem do poder não reconhece as diferenças, procurando a integração constante do que está "fora" do padrão. Em síntese o modo de o Estado tratar as diferenças é não as considerando como tais, mas procurando homogeneizá-las a partir de um padrão referencial do momento. Como a ordem vigente é igualar as diferenças, o padrão referencial passa a ser a competência tecnológica, direcionando as Políticas Públicas à produção do conhecimento tecnológico e à viabilidade econômica (Boneti, 2007).

Como resultado da correlação de forças sociais, as Políticas Públicas são construídas no decorrer do tempo, caracterizando o tipo de intervenção do Estado na realidade social. Portanto não se deve pensar estas sob uma ótica dicotômica, que considera o Estado separadamente da Sociedade Civil, as Políticas Públicas devem nascer do contexto desta e dos embates de forças e interesses.

\section{QUALIDADE DE VIDA URBANA: UMA NOVA FORMA DE PENSAR O URBANO}

A ideia de qualidade de vida introduz uma valorização de horizontes desejáveis para os grupos sociais, onde diferentes níveis de exigência e de aspirações conformam aspectos mais subjetivos e afeitos à percepção dos indivíduos. O conceito de qualidade de vida guarda relação com a satisfação das necessidades humanas, com a capacidade de uma comunidade desfrutar de uma vida média longa, de forma saudável. A tese de Vitte (2009) é que a garantia das necessidades básicas está longe de ser suficiente para a qualidade de vida plena ou para uma vida de qualidade, sendo de suma importância os fatores relativos à sociabilidade como suporte a uma percepção mais positiva da qualidade de vida. É importante salientar que estas práticas de sociabilidade vem sofrendo duros golpes nas cidades brasileiras, especialmente nas grandes metrópoles, devido ao crescimento da violência e à segregação socioespacial.

Embora a expressão qualidade tenho sido originalmente utilizada com um caráter individual, especialmente na área da saúde, é necessário lembrar que o planejamento governamental tem um caráter coletivo, e que as políticas públicas são sempre orientadas à grupos populacionais. Assim sendo, ao considerar a qualidade de vida numa perspectiva do planejamento e da gestão, essas necessidades devem ser satisfeitas por políticas públicas. 
As necessidades humanas são regidas por dois conjuntos de valores, os relacionados ao bemestar social e os relacionados à diferença. Os valores de bem-estar social têm vínculo com o bem-estar individual em função da saúde, segurança e riqueza, já os valores afeitos à diferença se referem a respeito, integridade, afeto e derivados das relações humanas. De acordo com a hierarquia de Maslow as necessidades se dividem em cinco níveis: o primeiro nível está relacionado às necessidades básicas de sobrevivência; o segundo corresponde às necessidades de segurança no ambiente; o terceiro relaciona-se à necessidade de pertencimento e amor, do afeto nas relações pessoais; o quarto nível é o da estima, relativo à necessidade de reconhecimento e posição social; e o quinto é o da autonomização (Vitte, 2009).

A percepção de bem-estar e qualidade de vida nem sempre tem relação direta com a felicidade objetiva, mensurada por índices de nutrição, saúde, renda per capita, educação etc. Ela está subordinada à percepção interna e ao julgamento que a pessoa faz da própria vida. Observa-se que nas sociedades democráticas ocorre uma relativa oferta de bem-estar social, porém as necessidades humanas relacionadas ao verbo amar são mais complexas e muitas vezes esquecidas no debate da qualidade de vida. Estes aspectos podem ser relacionados às identidades sociais: vínculos e contatos com a comunidade local, vínculos com a família, amizades, participação em organizações e associações e relações com os colegas de trabalho.

Uma característica importante é que as pessoas tendem a julgar a qualidade de seu ambiente mais pelo que percebem ser um bom vizinho do que pela condição física do bairro. A qualidade de vida urbana é associada a aspectos das necessidades básicas e do ambiente físico, da imagem vinculada à paisagem urbana.

A cidade é o lugar da manifestação do individual e da experiência coletiva, uma vez que existe uma multiplicidade de trocas que ajudam a produção da sociabilidade. É na cidade, como lugar, que ocorre a produção da vida, pelos modos de apropriação do espaço, e cada sociedade produz seu espaço de acordo com sua função social, os ritmos de vida, os modos de apropriação, projetos e desejos. A vida citadina se revela como espaço passível de ser sentido, pensado, apropriado e vivido pelo indivíduo, mediado pelo corpo que cria/percebe os referenciais necessários para dar sentido à experiência. A cidade pode ser entendida como um espaço concebido, vivido e percebido, agregando símbolos e valores elaborados por meio de impressões e experiências pessoais, mas também coletivas. Os indivíduos interagem com o mundo por meio das atividades cotidianas, na busca de satisfazer suas necessidades e desejos (Vitte, 2009).

O bairro, a praça, a rua e o pequeno comércio aproximam os moradores. Tais lugares podem ser mais que pontos de trocas de mercadorias, podem possibilitar o encontro, reforçando a sociabilidade. Ao vivenciar a cidade o indivíduo percebe o meio e adquire uma imagem própria sobre o espaço, imagem esta que pode diferir de outros indivíduos. As paisagens urbanas constituem elementos representativos da qualidade de vida. Acessibilidade, fluidez, limpeza, iluminação, qualidade das edificações, tamanho das residências, presença de áreas verdes e 
disponibilidade de serviços básicos são indicativos do grau de satisfação de necessidades básicas.

A consciência individual é um produto social, bem como as subjetividades, e o coletivo atribui ao espaço ocupado o seu sentido, onde coexiste uma dimensão subjetiva na qual ocorre interferências de fatores socioculturais, que afetam as percepções individuais mediadas por aquelas.

As cidades contemporâneas vêm assumindo características muito perversas, tornando-se muitas vezes inumanas. No entanto, pode-se empreender mudanças necessárias ao mobilizarse coletivamente as energias e desprendendo-se de uma imagem de cidade como um inferno. O bem-estar e uma alta qualidade de vida dever ser um direito do cidadão, e é por meio da política que os cidadãos lutam por estes direitos e não o contrário (Vitte, 2009).

O Estado, por meio de suas práticas, induz e provoca marcantes transformações nos usos e funções dos lugares na cidade. Ao direcionar investimentos em infraestruturas pode gerar desigualdades, já que no contexto da sociedade capitalista pode intervir aprofundando um processo de valorização diferencial da terra urbana. Qualquer intervenção na cidade capitalista não é necessariamente excludente, uma vez que todos os governos, o tempo todo, intervêm na cidade. Tais intervenções podem ser mais ou menos inclusivas de acordo com as forças sociais e políticas que estão operando no momento na realidade local. É preciso dar nova vida à cidade, fazer dela um espaço apropriável para a vida e para todos.

Países como o Brasil e outros da América Latina, onde existe uma péssima distribuição de renda, analfabetismo e baixo grau de escolaridade, bem como condições ambientais e de habitação precárias, as condições de vida e saúde populacional sofrem uma influência muito forte. $O$ debate sobre a qualidade (condições) de vida e saúde tem um forte histórico na saúde coletiva (Buss, 2000). No entanto, o desafio não é apenas mostrar que a qualidade/condições de vida afeta a saúde, influenciando fortemente a qualidade de vida, mas sobretudo investigar quais as intervenções, especialmente quais as políticas públicas intersetoriais, podem influenciar favoravelmente a qualidade de vida urbana.

\section{A PROMOÇÃO DA SAÚDE COMO REORIENTAÇÃO DE POLÍTICAS PÚBLICAS}

O conceito de promoção de saúde reforça a importância da ação ambiental e política bem como do estilo de vida como eixos norteadores. Entende-se por promoção de saúde um

(...) processo de capacitação da comunidade para atuar na melhoria de sua qualidade de vida e saúde, incluindo uma maior participação no controle deste processo. Para atingir um estado de completo bem-estar físico, mental e social os indivíduos e grupos devem saber identificar aspirações, satisfazer necessidades e modificar favoravelmente o meio ambiente. A saúde deve ser vista como um recurso para a vida, e não como objetivo de viver. Nesse sentido, a saúde é um conceito positivo, que enfatiza os recursos sociais e pessoais, bem como as capacidades físicas. Assim, a promoção da saúde não é responsabilidade exclusiva do setor saúde, e vai para além 
de um estilo de vida saudável, na direção de um bem-estar global. (Carta de Otawa, 1986: $s / p)$

O foco da saúde muda, deixando de ser um objetivo a ser alcançado, tornando-se um recurso para o desenvolvimento da vida.

O movimento sanitarista exerceu grande influência nas políticas públicas dos países desenvolvidos até o final do século XIX, mediante leis e grandes obras de engenharia. No início do século XX iniciou-se a era bacteriológica, onde a ênfase passou a ações de saúde com foco na prevenção pessoal. Até a década de 1970 as políticas públicas para a saúde, tanto nos países desenvolvidos como nos em desenvolvimento, estiveram dominadas por essa orientação, concentrando as ações na construção de grandes hospitais e superespecialistas (Westphal, 2000).

No início da década de 1970, na maioria dos países, o setor saúde começou a entrar em crise, devido aos altos custos da medicina curativa que utilizava alta tecnologia. Essa crise foi paulatinamente levando ao surgimento de estratégias baseadas em novos conceitos, iniciando um período chamado de "nova saúde pública". Esta nova saúde pública surgiu do questionamento do poder da medicina na resolução sozinha dos problemas de saúde e do reconhecimento de que tudo que existe é produto da ação humana, em contraposição à hegemonia da terapêutica. Como consequência surgiu uma nova era de interesse social e político na saúde pública. A saúde de um indivíduo ou de uma comunidade depende também das coisas que o homem criou e faz, das interações dos grupos sociais, das políticas adotados pelo governo e também dos mecanismos de atenção à doença.

A partir da Declaração de Alma-Ata sobre Atenção Primária à Saúde em 1977, inúmeras iniciativas da Organização Mundial da Saúde (OMS) culminaram com o projeto Cidades Saudáveis, em 1986. Os elementos principais dessas iniciativas foram o interesse pela pobreza, necessidade de reorientação dos serviços de saúde, a importância da participação comunitária e o desenvolvimento de coalizões entre o setor público, setor privado e o voluntariado.

Na década de 1980, em Toronto no Canadá, aconteceu o congresso "Para Além da Assistência à Saúde", que atraiu muitos interessados, visto que o Canadá já possuía inúmeras iniciativas que se caracterizavam como inseridas no Movimento Cidades Saudáveis. Os representantes do escritório europeu da OMS assumiram como novo paradigma este projeto estruturante, elaborando uma proposta de projeto de Promoção da Saúde, selecionando diversas cidades para adotarem os princípios definidos na proposta "Saúde para Todos" da OMS (Westphal, 2000).

A promoção da saúde surge então como uma reação à acentuada medicalização da vida social e como resposta que articula diversos recursos tecnológicos e posições ideológicas. Passa a ser um enfoque político e técnico em torno da questão da saúde como qualidade de vida. Seu conceito moderno surge e se desenvolve incluindo diversos procedimentos para a promoção da saúde: bom padrão nutricional; atendimento das necessidades para o desenvolvimento 
ótimo da personalidade; educação sexual; moradia adequada; recreação e condições agradáveis no lar e no trabalho.

De acordo com Buss (2000), pode-se agrupar as diferentes conceituações da promoção da saúde em duas vertentes. Na primeira, consiste em atividades dirigidas à transformação dos comportamentos dos indivíduos, focando nos seus estilos de vida, ambientes e territórios onde se encontram, considerando a sua cultura particular, por consequências as ações se dariam no nível pessoal. A segunda vertente sustenta-se no entendimento que a saúde é produto de um amplo espectro de fatores relacionados à qualidade de vida, incluindo aí a alimentação e nutrição, habitação e saneamento, condições de trabalho e oportunidades educacionais, ambiente físico e apoio social, além dos cuidados com a saúde de modo geral, exigindo ações mais globais e abrangentes.

\section{CIDADES SAUDÁVEIS: REORIENTAÇÃO DAS POLÍTICAS PÚBLICAS PARA A QUALIDADE DE VIDA}

As cidades, num determinado momento histórico, começaram a se organizar em razão do mercado e dos interesses do capital, observou-se a mercantilização do espaço, a organização da cidade materializando a divisão da sociedade em classes e um poder centralizado. Essa redefinição do espaço urbano trouxe importantes reflexos para a vida na cidade: aglomeração e competição nos espaços, luta pelo espaço construído em torno das melhores localizações, inclusão e exclusão, com zonas de pobreza e riqueza, evidenciando uma segregação socioespacial, poluição de ambientes, gerando agravos e problemas de saúde (Akerman et al, 2014).

Os principais pressupostos do Movimento Cidades Saudáveis estão relacionados ao movimento sanitário europeu do século XIX, que já reconhecia os governos locais das cidades e as associações comunitárias como importantes agentes junto aos problemas de saúde. Com o processo de urbanização europeu ocorreu uma deterioração das condições de vida das populações carentes, gerando um estado de vulnerabilidade. Como os governos resistiam a implementar mudanças foi criada na Inglaterra a Associação pela Saúde das Cidades, reunindo pessoas organizadas para pressionar as autoridades. Esta associação propunha mudanças nas leis com objetivo de melhorar as condições sanitárias e estabelecer uma coalização intersetorial para a saúde. Entre seus objetivos estava a melhoria da situação física das cidades, dos padrões de habitação, regulações higiênicas, pavimentação das ruas e saneamento ambiental (Westphal, 2000).

O conceito de Cidades Saudáveis entende a cidade como uma estrutura geográfica na qual se vive e se trabalha, entendida também como uma entidade administrativa, daí alguns locais e autores preferirem o termo Municípios Saudáveis. Neste território diferentes sistemas interagem, buscando o equilíbrio urbano em meio a conflitos de poder e de relações. As cidades assim, assumem papel de atores sociais, já que os cidadãos que nela habitam ocupam 
um espaço simbiótico e se organizam politicamente como sociedade civil. O espaço ocupado também é simbólico, integrando seus habitantes culturalmente, possibilitando a formação de uma identidade coletiva, que dinamiza as relações, convertendo a cidade em espaço que responde a objetivos econômicos, políticos e culturais de sua época. A proposta de Cidades Saudáveis surgiu em função destas concepções urbanas, embora tenha sido compreendida de diversas maneiras.

Cidades saudáveis é o nome que se dá a um projeto de desenvolvimento social, que tem a saúde e suas múltiplas determinações como centro das atenções. Este movimento luta por um estilo de desenvolvimento sustentável, sua concepção esteve ligada ao ideário da Nova Saúde Pública, ou melhor dizendo, da produção social da saúde. O objetivo estratégico da proposta era motivar governos e sociedades para a melhoria das condições de vida e saúde da população urbana, transformando as relações excludentes e conciliando ao mesmo tempo os interesses econômicos e o bem-estar social. O Movimento também focaliza a participação popular como forma de mobilização e de democratização, buscando mudanças na forma de gerir os diferentes níveis de gestão, especialmente o local (Westphal, 2000).

Para participar do Movimento Cidades Saudáveis, seus poderes executivo e legislativo, deveriam adotar políticas públicas que solucionassem os problemas apontados por um diagnóstico de situação, sempre de forma integrada e intersetorial. Como na democracia moderna as políticas nem sempre são selecionados, elaboradas e adotadas racionalmente, uma vez que ocorre uma mediação no processo de interação e negociação entre os atores que acompanham a definição das políticas, é necessária a participação da população, que vive e sente os problemas de seu cotidiano. Esta participação deve ocorrer em todo o projeto, por meio de grupos organizados e da sociedade civil.

Mais que um conceito, é uma estratégia de promoção da saúde cujo objetivo é a melhoria da qualidade de vida da população. Esta qualidade depende de suas condições de existência, do seu acesso a certos bens e serviços econômicos e sociais como: emprego e renda, educação básica, alimentação adequada, acesso a bons serviços de saúde, saneamento básico, habitação, transporte de boa qualidade etc. Para que uma cidade se torne saudável deve esforçar-se para proporcionar: um ambiente físico limpo e seguro; um ecossistema estável e sustentável; alto suporte social, sem exploração; alto grau de participação social; necessidades básicas satisfeitas; acesso a experiências, recursos, contatos, interações e comunicações; economia local diversificada e inovativa; orgulho e respeito pela herança biológica e cultural; serviços de saúde acessíveis a todos e um alto nível de saúde (Adriano et al, 2000).

\section{CONCLUSÃO}

O processo de urbanização das cidades trouxe novos desafios, impactando diretamente nas condições de vida das populações, especialmente das mais vulneráveis. Entende-se que a melhor forma de impactar sobre a coletividade é por meios das políticas públicas, uma vez que 
estas são produzidas do embate político entre diferentes classes e poderes em jogo na arena social.

A promoção da saúde surge como uma nova orientação no setor saúde, que ao extrapolar sua própria área de conhecimento, abrange questões mais amplas para o desenvolvimento e obtenção da qualidade de vida. O movimento das cidades saudáveis, ao considerar o território como local de ação e construção, busca agir por meio da construção e efetivação de políticas públicas com foco na participação social e promoção da saúde visando impactar na qualidade de vida urbana.

Outros temas que necessitam de maior aprofundamento, para melhor compreensão da questão, são o da participação social e do empoderamento dos agentes responsáveis pela saúde, no caso, a própria população. Assim poderá ser construído um quadro teórico mais amplo sobre a problemática em questão.

\section{AGRADECIMENTO}

Agradecemos à Coordenação de Aperfeiçoamento de Pessoal de Nível Superior (Capes) pelo apoio financeiro mediante bolsa de doutoramento.

\section{REFERÊNCIAS BIBLIOGRÁFICAS}

ADRIANO, J. R. et al. A construção de cidades saudáveis: uma estratégia viável para a melhoria da qualidade de vida? Ciência \& Saúde Coletiva, 5 (1): 53-62, 2000.

AKERMAN, M. et al. Avaliação em promoção da saúde: foco no "município saudável". Rev Saúde Pública, 36(5): 63846, 2000.

BONETI, L. W. Políticas públicas por dentro. 2.ed. Ijuí: Ed. Unijuí, 2007.

BUSS, P. M. Promoção da saúde e qualidade de vida. Ciência \& Saúde Coletiva, 5 (1): 163-177, 2000.

CARTA DE OTTAWA. Primeira Conferência Internacional sobre Promoção da Saúde, 1986. In: BRASIL, Ministério da Saúde. As cartas da Promoção da Saúde. Brasília: Ministério da Saúde, 2002.

VITTE, C. C. S. A qualidade de vida urbana e sua dimensão subjetiva: uma contribuição ao debate sobre políticas públicas e a cidade (pp 89-110) In: VITTE, C. C. S.; KEINERT, T. M. M. Qualidade de Vida, Planejamento e Gestão Urbana: discussões teórico-metodológicas. Rio de Janeiro: Bertrand Brasil, 2009.

WESTPHAL, M. F. O movimento cidade/municípios saudáveis: um compromisso com a qualidade de vida. Ciência \& Saúde Coletiva, 5 (1): 39-51, 2000. 